\title{
A Atenção Voluntária na Construção de Conceitos Trigonométricos em Ambientes de Geometria Dinâmica
}

\section{Title: The Voluntary Care in Construction in Trigonometric Concepts Construction Dynamic Geometry Environments}

\author{
Margarete Farias Medeiros \\ UFRGS \\ margarete.medeiros@sombrio.ifc.edu.br
}

\author{
Débora Valletta \\ UFRGS \\ dvalletta@uol.com.br
}

\author{
Evandro Bitencourt Magagnin \\ IFC - Campus Avançado Sombrio \\ evandro_bitencourt@hotmail.com
}

Elizete Maria Possamai Ribeiro IFC - Campus Avançado Sombrio elizete.ribeiro@sombrio.ifc.edu.br
Katelyn Luzia dos S. Daboit

IFC - Campus Avançado Sombrio

katelyndaboit@hotmail.com

\section{Resumo}

O artigo apresenta os resultados de pesquisa do projeto sobre a utilização de ambientes de Geometria Dinâmica (GDE), obtidos por meio de aplicações de sequências didáticas. O objetivo foi investigar o tempo de atenção voluntária dos estudantes quando submetidos aos ambientes de GDE na exploração de conceitos trigonométricos. Para a realização das sequências didáticas foi utilizado o software GeoGebra, um software de Ambiente de Geometria Dinâmica livre que permite a identificação de conceitos algébricos e geométricos simultaneamente em uma interface interativa e simples. A metodologia utilizada, quanto à abordagem do problema, definiu-se como qualitativa, quanto aos objetivos de forma exploratória e quanto à técnica de pesquisa, estudo de caso. Para dar suporte utilizou-se a teoria Sócio-Histórica de Vygotsky, e para tratar das questões semióticas fundamentou-se na teoria de Duval. A partir da aplicação do projeto destacou-se a importância da utilização destes ambientes para a obtenção da atenção voluntária dos estudantes no processo de construção de conceitos trigonométricos.

Palavras-Chave: atenção; concentração; software; trigonometria.

\begin{abstract}
This article presents the results of the project, obtained through didactic sequences applications. The objective was to investigate the voluntary attention span of students when subjected to Dynamic Geometry Environment (GDE) in the exploration of trigonometric concepts. To carry out the didactic sequences was used GeoGebra software, a free Dynamic Geometry Environment software that allows the identification of algebraic and geometric concepts simultaneously in an interactive interface and simples. The methodology used, regarding the approach of the problem, was defined as qualitative, regarding the objectives of exploratory form and as for the research technique, case study Para support the research used the Socio-Historical theory of Vygotsky, and to address the semiotic issues was based on the theory of Duval. From the implementation of the project highlighted the importance of using these environments to obtain the voluntary attention of students in the trigonometric concepts construction process.
\end{abstract}

Keywords: attention, concentration, software, trigonometry.

Cite as: Medeiros, M. F., Valletta, D., Ribeiro, E. M. P., Daboit, K. L. S., Magagnin, E. B. (2017). The Voluntary Care in Construction in Trigonometric Concepts Construction Dynamic Geometry Environments. (A Atenção Voluntária na Construção de Conceitos Trigonométricos em Ambientes de Geometria Dinâmica). Brazilian Journal of Computers in Education (Revista Brasileira de Informática na Educação - RBIE), 25(1), 77-93. DOI: 10.5753/RBIE.2017.25.01.77 


\section{Introdução}

Este artigo é resultado da experiência realizada no projeto de pesquisa desenvolvido no ano de 2014, no Instituto Federal Catarinense (IFC) - Campus Avançado Sombrio onde foram estudadas as consequências da utilização dos Ambientes de Geometria Dinâmica (DGE) no ensino e aprendizagem da Matemática escolar. Em especial no que se refere à atenção voluntária dispensada pelo estudante quando submetido à utilização destes ambientes para a construção de conceitos trigonométricos. Consideramos que a atenção seja um tipo de concentração e, que apresenta instabilidade relacionada à intensidade e temporalidade. Neste sentido, verificamos o tempo de concentração na realização das atividades e se esta instabilidade interfere na construção dos conceitos matemáticos estudados.

Para discutirmos sobre a formação do pensamento conceitual é necessário compreendermos os processos cognitivos tais como: percepção, atenção, categorização e generalização, os quais estão associados ao processo de formação de conceitos (Pimentel, 2012). Para tanto, neste projeto de pesquisa buscamos estudar a atenção, um dos processos psíquicos básicos e que dá subsídio à constituição dos demais. As "disfunções nesses mecanismos são também responsáveis pelo desenvolvimento de desordens cognitivas" (Pimentel, 2012, p.51). Consideramos que estas desordens cognitivas interferem no ensino e aprendizagem da Matemática escolar.

Para investigar o processo cognitivo da atenção voluntária foram utilizadas referências da teoria Sócio-histórica de Vygotsky (2011) e, sobre os registros de representação semiótica fundamentamo-nos na teoria de Duval (2011).

Pesquisas desenvolvidas no Brasil e também no exterior (Gravina, 1996; Trouche, 2000; Medeiros, 2012; Abar, 2013; Silva, 2015) acerca da Tecnologia Digital de Informação e Comunicação (TDIC) têm contribuído para melhorar a qualidade do ensino e aprendizagem e, a partir destas, estabelecemos um ambiente propício para sua aplicação, com sequências de atividades elaboradas para a captação da atenção dos estudantes participantes das oficinas. $\mathrm{O}$ pensamento conceitual é uma conquista que depende do esforço do indivíduo e também do contexto no qual ele está inserido (Pimentel, 2012).

A pesquisa tem como objetivo responder a seguinte questão: De que forma o software GeoGebra pode contribuir para captar a atenção e aumentar o tempo de concentração do estudante na construção de conceitos Trigonométricos? Logo, o objetivo geral foi utilizar o software GeoGebra como recurso tecnológico para possibilitar, talvez, a captação da atenção e aumento do tempo de concentração dos estudantes, para que estes construíssem os conceitos matemáticos abordados. A partir da construção de desenhos de objetos matemáticos no software GeoGebra os estudantes se apropriaram dos conceitos por meio da atividade prática tornando-se o sujeito no processo de aprendizagem.

Para tal, a proposta prática foi utilizar o software GeoGebra com os estudantes não somente como um recurso tecnológico, mas como um importante recurso para apoiá-los [os estudantes] no desenvolvimento dos conceitos matemáticos. Sabe-se que o software por si só não faz Matemática (Abar, 2013).

Trata-se de uma pesquisa qualitativa e de cunho exploratório. Como instrumentos para coleta de dados foram utilizados: questionários on-line e observação do tipo não estruturada, ou seja, relatamos de acordo com os acontecimentos, sem previsão de ocorrências. Durante o percurso metodológico os pesquisadores observaram a construção no software, a apropriação dos conceitos pelos estudantes e as atividades realizadas nas oficinas, buscando auxiliar aos estudantes para os questionamentos apontados durante a prática, sendo que, estas ações permitiram-nos [os pesquisadores] uma aproximação entre os sujeitos envolvidos, 
proporcionando qualidade no presente estudo.

Para descrever as etapas desenvolvidas a segunda seção apresenta as reflexões teóricas. A terceira é destinada à descrição da metodologia aplicada e a quarta dispõe os resultados e as discussões. E finalmente, na quinta seção, os autores apresentam as considerações finais e, discutem possíveis aplicações e melhorias para o projeto de pesquisa em questão.

\section{Reflexões Teóricas}

Por meio da atenção dispensada nas atividades pode-se ter acesso ao conhecimento e conseguir agregar novos conceitos aos esquemas mentais. O processo de formação de conceitos é fundamental para desenvolver as funções psicológicas superiores tais como: atenção deliberada, memória lógica e a abstração.

Pimentel (2012) afirma que "um dos processos psíquicos básicos que subsidia a constituição dos demais é a atenção, e que os mecanismos atencionais são fundamentais para os processos cognitivos e de aprendizagem”. Segundo Vygotsky (2001, apud Pimentel, 2012, p.51), entende-se por atenção como sendo uma "atitude do organismo de adaptar os órgãos [...] aos estímulos, de modo a selecionar uma parte de tais estímulos, colocando-os em condições diferentes das demais". Desta forma quando o estudante estiver com a atenção voltada para alguma situação, significa estar distraído para as diversas situações que estarão acontecendo ao seu redor.

A atenção está diretamente relacionada com a concentração e a percepção, que são fundamentais no processo de aprendizagem e, por meio delas, se torna possível compreender os conceitos por meio dos sistemas semióticos que os representam. "Há uma pluralidade de registros de representação de um mesmo objeto, e a articulação desses diferentes registros é condição para a compreensão em matemática (...)" (Machado, 2010, p.31). Tal pluralidade contribui para o aumento das capacidades cognitivas dos sujeitos e em seguida as suas representações mentais. Sendo assim, o professor ao utilizar mais signos para explorar determinado conceito propiciará aos estudantes diversas oportunidades de aprendizagem.

No que se refere ao desenvolvimento das representações mentais "[...] efetua-se como uma interiorização das representações semióticas de mesma maneira que as imagens mentais são uma interiorização das percepções" (Duval, 2009, p.17). Logo, entende-se por percepção "um processo psíquico complexo que envolve análise, síntese, classificação, categorização e tomada de decisão" (Luria apud Pimentel, 2012, p.54) e, está ligada às funções de abstração e generalização da linguagem - a percepção obtida por meio da atenção tem papel fundamental na formação dos conceitos.

Estes são parte dos processos mentais superiores "formados a partir de processos psíquicos que envolvem a percepção, atenção, classificação, abstração e generalização dos objetos, imagens e signos" (Pimentel, 2012, p.50). A obtenção pelo professor da atenção do estudante lhe requer: planejar, preparar e organizar os recursos, a serem utilizados na exploração dos conceitos. A apresentação dos recursos deve ocorrer de modo a obter a atenção do estudante, "evitando exposições verbais e/ou atividades prolongadas, fazendo com que os momentos de maior atenção coincidam com os dos trabalhos mais importantes" (Pimentel, 2012, p.53).

Deve então o professor dispor da tecnologia digital (TD) para obter a atenção do estudante? "A presença do computador, a aula ganha um novo cenário, refletindo-se na relação do professor com os estudantes e no papel desempenhado pelos demais atores presentes" (Penteado, 1997). Como esta inserção da tecnologia na sala de aula pode influenciar na aprendizagem? O uso de tecnologias influencia na dinâmica da aula? A utilização do software 
capta a atenção do estudante durante toda a atividade desenvolvida? Somente a introdução de um software na sala de aula garante a construção do conhecimento por parte do estudante? Estas questões serviram para nortear as atividades do projeto.

Pesquisas (Papert, 1994); Gravina, 2001; Miskulin, 2008; Medeiros, 2012), apontam que a utilização de software é uma alternativa para facilitar a mobilização da atenção no estudante, no entanto, cabe ao professor analisar os tipos de softwares convenientes ao conceito estudado. Deve-se observar aspectos técnicos tais como: "a interface, diálogo entre o usuário e o computador, apresentação visual do software, 'esforço mental' requerido do usuário, tipo de resposta do sistema, (...) são fundamentais para a qualidade geral do software" (Valente,1999, p.87). No software com "educacional, a fundamentação teórico-pedagógica requer especial atenção".

Enfatizamos que a presença da TD na sala de aula exige um novo perfil de professor e uma gestão do tempo e do espaço em sala de aula (Trouche, 2000), uma mudança na prática docente (Borba \& Penteado, 2007). "Uma aula de Matemática onde o conhecimento não é utilizado, mas simplesmente empilhado como tijolos formando um edifício morto, não há qualquer espaço para experimentações significativas” (Papert, 1994, p.71).

Papert (1994) afirma que a escola não possui em sua natureza institucional a concepção de que o professor exerce um papel criativo, e sim, como profissionais [os professores] técnicos. Por outro lado, o autor destaca que o professor deve assumir seu papel criativo e de aprendizes, que experimentam diferentes situações de aprendizagem a fim de desenvolver habilidades e competências tecnológicas para se beneficiarem das possibilidades dos computadores, e consequentemente interagindo com seus estudantes. Papert (1994) afirma ainda que as pequenas ações e atitudes de um professor podem semear progressos em uma turma.

É necessário que o professor acompanhe estes avanços tecnológicos indo mais além do que apenas saber lidar com os computadores. Para tanto, o professor deverá atuar fazendo com que o estudante seja o sujeito da ação. E com a utilização da TD torna-se possível implementar esta nova forma de atuar. Diante destas observações cumpre elencarmos alguns questionamentos: O professor estará disposto a dispensar esforços e sacrifícios para tal atuação? Pode-se sentir exposto às atividades não planejadas as quais o software poderá levantar? Os estudantes podem saber mais sobre a utilização dos computadores do que o professor? Isso posto, qual será a atitude do professor? A sociedade entende que há necessidade de apoiar o perfil deste professor?

Hoje, as informações em excesso, uma variedade e infinidade de fontes e diferentes visões de mundo, ensiná-los [os estudantes] se tornou mais complexo, mais desafiador diante desta diversidade (Moran, 2004). A ubiquidade da informação exige, portanto, que todo o processo de ensino e aprendizagem seja repensado (Valletta, 2015).

Com o avanço das tecnologias móveis e a possibilidade de utilização de softwares nas interações educacionais, e estas se fazendo presente cada vez mais em sala de aula, evidenciamos que o professor não pode ficar alheio a estes fatos, é necessário usufruir destes recursos. O avanço tecnológico trouxe progressos para as mais diversas áreas do conhecimento, inclusive para a educação. Entre as possibilidades tecnológicas destacam-se, as plataformas digitais, que podem mapear as habilidades cognitivas (Valletta, 2016). Consideramos que a tecnologia deva ser utilizada como um instrumento facilitador da aprendizagem, um auxílio ao professor no seu ensino e ao estudante em sua aprendizagem.

Nesse sentido, sugerimos a utilização do software GeoGebra, o qual é um software gratuito, de livre acesso, e de fácil utilização e instalação (Medeiros, 2012). Diferencia-se dos demais softwares por associar a Álgebra e a Geometria com mesmo grau de importância, disponibilizando simultaneamente janelas [ferramentas de apoio] para trabalhar nestas duas 
áreas. Apresenta diferentes tipos de registros semióticos: algébrico, geométrico e o discursivo. Sendo que, a passagem de um registro para o outro, é o que faz com que o estudante aprenda, ou seja, utilizar-se da conversão de registros (Duval, 2011). Logo, o software possibilita ao estudante efetivar a atividade prática construindo conhecimento sob os conceitos matemáticos.

Este software se opõe aos tipos Computer Aided Instruction (CAI) ou Instrução Auxiliada pelo Computador (Papert, 1994). Esse tipo de software, o CAI, refere-se a programar o computador para trabalhar os tipos de exercícios que são aplicados de forma "tradicional" por um professor em um quadro-verde, em um livro didático ou por meio de uma folha de exercícios. Entendemos que este procedimento não contribui e nem desafia o estudante a construir conhecimento, não justificando a utilização de computadores para aplicar tal atividade. Tal manipulação deve-se ao fato de que esta atividade poderia ser desenvolvida sem a necessidade de um computador.

O software GeoGebra oportuniza a realização de atividades educativas, as quais seriam impossíveis, sem o apoio do computador - criação de atividades de movimentação e dinamismo nas construções geométricas. Além de permitir ao estudante ir "além" do que o professor está propondo em sala de aula. Propicia ao estudante adentrar em caminhos até então desconhecidos pelo mesmo e, talvez pelo professor; oportuniza conjecturar, refletir sobre sua ação, abstrair e generalizar. Essas são atividades essenciais em Matemática, além da conversão de registros de representação semiótica (Duval, 2011). Trata-se da passagem de um registro para outro, por exemplo, do registro algébrico para o registro gráfico e vice-versa.

Os autores Medeiros (2012) e Gravina (2015) discutem em suas pesquisas sobre o potencial deste software para o ensino e aprendizagem da Matemática escolar, no que se refere à construção dos conceitos geométricos. Dentre as principais ferramentas destaca-se a "estabilidade sob a ação de movimentos", ou seja, a construção quando submetida à ferramenta "Mover" oferecida pelo software, não perde as propriedades impostas inicialmente à construção, bem como às relações matemáticas estabelecidas a partir de suas propriedades. Esse é, com certeza, um recurso poderoso para a construção do conhecimento em Matemática. Esses recursos oportunizam e permitem aos estudantes a construírem as suas hipóteses e comprovarem a sua veracidade e também a avançar o conhecimento na questão conceitual, potencializando a aprendizagem com sentido e significado durante o percurso da aprendizagem.

Destaca-se também como uma das características importantes deste software, o estudo dos conceitos trigonométricos. De acordo com a vivência por mais de vinte e cinco anos, de dois autores do presente artigo, no ensino da Matemática escolar, este é com certeza um dos conceitos, dentre os quais os estudantes sentem mais dificuldades para a sua abstração. E por meio deste software, o estudante obtém perfeitas construções, relacionando o ciclo trigonométrico aos gráficos das funções trigonométricas. Além de, apresentar em tempo real os diferentes registros do mesmo objeto matemático estudado. Esses registros podem ser dinâmicos, ou seja, o estudante pode movimentá-los por meio de uma velocidade estabelecida por ele [o estudante].

O software disponibiliza outras ferramentas para o estudante, a possibilidade de mudança dos parâmetros das funções por meio do 'Controle Deslizante'. Neste caso, por exemplo, das funções trigonométricas (Equação 1), $\operatorname{com} a, b, c$ e $d$ números reais e $b$ e $c$ não nulos, o software oportuniza a mudança dos valores de $a, b, c$ e $d$, alterando o registro algébrico na janela da álgebra e consequentemente o registro geométrico na janela de visualização.

$$
y=a+b \cdot \sin (c \cdot x+d)
$$

Neste caso, o gráfico da função dada de acordo com os parâmetros escolhidos é apresentado na Janela de Visualização (Figura 1). 


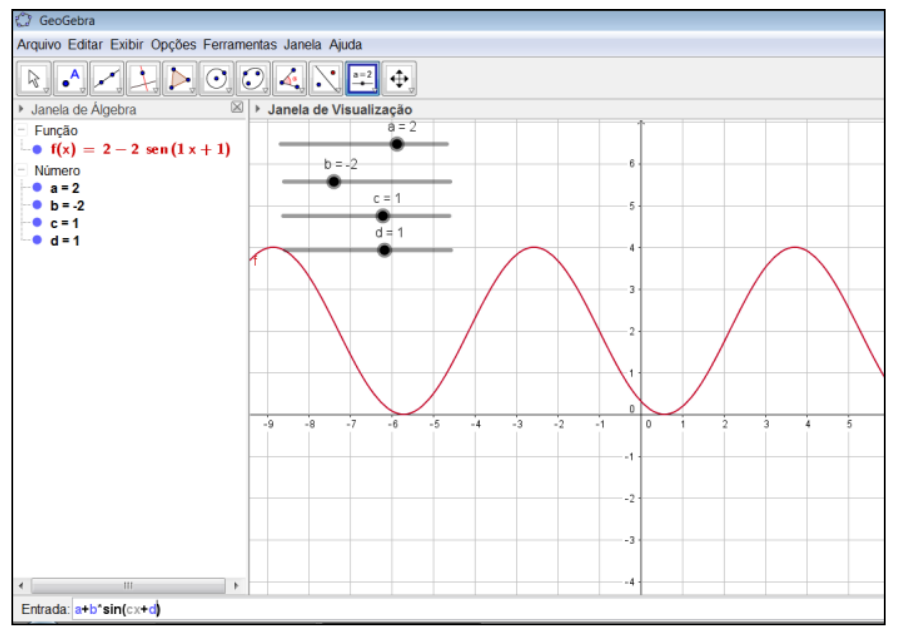

Figura 1: Uso do Controle Deslizante

Esta ferramenta [Controle Deslizante] (Figura 1) possibilita a representação de diversas funções e a possibilidade do estudante verificar o que cada parâmetro influencia na função dada. É possível examinar os deslocamentos efetuados na representação gráfica a cada mudança efetuada no parâmetro em questão.

Com a opção do 'Controle Deslizante' pode-se animar o controle e a função irá desenvolver-se de acordo com as alterações dadas por ele. É a oportunidade dada ao estudante para que ele tenha o domínio e escolha das funções as quais gostaria de observar. O estudante, neste caso, é o centro da aula, ele estará em ação, e isso levará a construção de seu próprio conhecimento.

$\mathrm{Na}$ próxima seção faz-se a apresentação dos procedimentos metodológicos e dos instrumentos utilizados para a coleta e a análise dos resultados obtidos, a partir da realização de sequências didáticas utilizando-se este software de Geometria Dinâmica - o GeoGebra.

\section{Procedimentos Metodológicos}

A metodologia utilizada no desenvolvimento da pesquisa, quanto à abordagem do problema, definiu-se como qualitativa, quanto aos objetivos de forma exploratória e quanto à técnica de pesquisa, estudo de caso. O estudo de caso consiste no detalhamento aprofundado de um determinado contexto, sujeitos e/ou entre outros elementos "[...] que possam ser objetos do estudo ou fontes de dados e, [...] tentando avaliar o interesse do terreno ou das fontes de dados para os seus objetivos." (Bogdan \& Biklen, 2013, p.90). Logo, a escolha do contexto educativo foi intencional.

Realizamos a aplicação de sequências didáticas, tendo como recurso tecnológico o software GeoGebra. Participaram da pesquisa oito estudantes voluntários do segundo ano do curso Técnico em Informática Integrado ao Ensino Médio, com a idade média de 16 anos. Os estudantes deste curso foram convidados a participar do projeto e, oito deles aceitaram representaram aproximadamente a proporção de 0,14 do total de 56 estudantes. Eram estudantes com rendimento escolar diversificado na disciplina de matemática, ou seja, dentre os participantes existiam alunos com rendimento baixo, médio e alto. Referente ao domínio da tecnologia informática é possível afirmar que a dominavam e, como eram discentes de um curso nesta área, não sentiram [os estudantes] nenhuma dificuldade para a realização dos trabalhos concernente ao uso da informática. 
De acordo com a ética na pesquisa com seres humanos, enviamos aos responsáveis dos estudantes, um Termo de Consentimento livre e Esclarecido (TCLE) contendo as informações do projeto e da pesquisa. Logo, solicitamos o consentimento para a divulgação de imagens, produções, entre outras atividades desenvolvidas ao longo desta pesquisa.

Os cinco encontros foram realizados no laboratório de informática do IFC (Figura 2). Os bolsistas foram orientados pelo coordenador do projeto e desenvolveram as sequências didáticas juntamente aos estudantes. Um dos bolsistas era integrante da turma em que foi aplicado o projeto e o outro um acadêmico do Curso Superior de Licenciatura em Matemática.

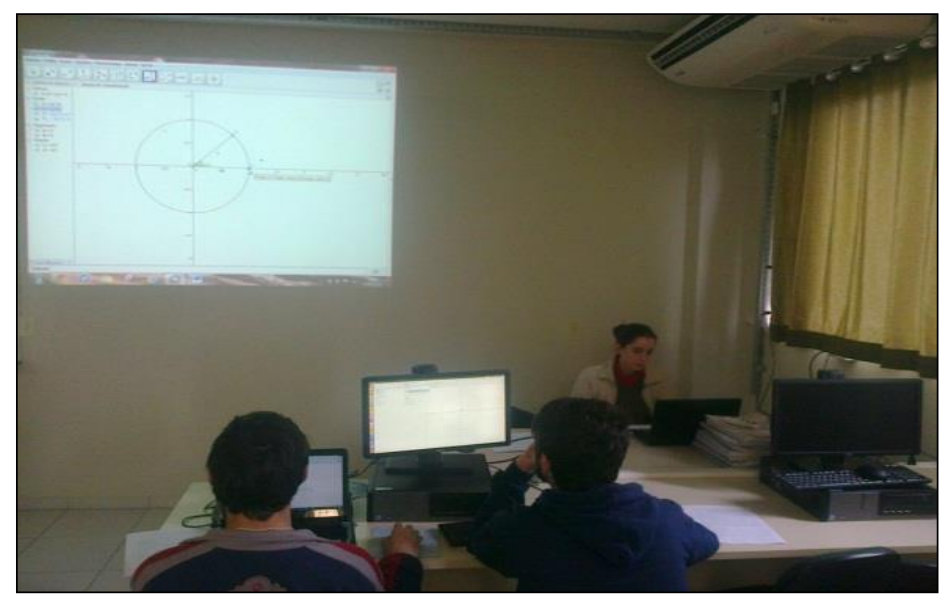

Figura 2: Aplicação do projeto

As sequências didáticas (Figura 3) foram elaboradas pelos bolsistas e avaliadas pelo coordenador antes da aplicação das atividades. A partir de cada encontro as sequências didáticas foram analisadas e adaptadas na medida em que as atividades eram desenvolvidas pelos estudantes. 


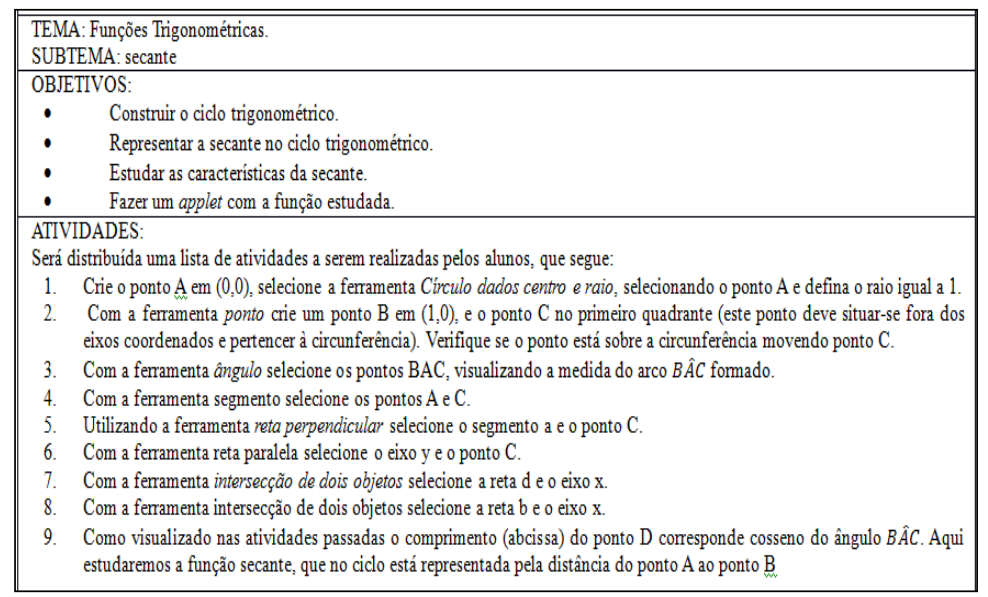

Figura 3: Recorte de sequência didática

Os conceitos trabalhados foram relativos às Funções Trigonométricas, restringindo-se aos temas voltados à trigonometria do respectivo ano dos estudantes (conforme o currículo da instituição) (Figura 4). Os conceitos foram abordados em duas partes: primeiro a trigonometria do ciclo trigonométrico e na sequência as funções trigonométricas.

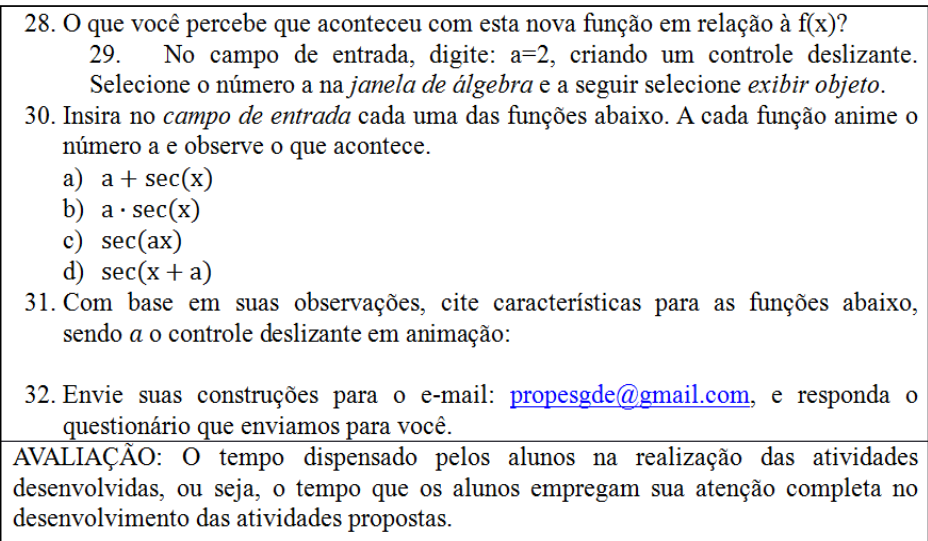

Figura 4: Recorte de sequência didática

O objetivo foi desenvolver uma atividade educativa diferente do que era trabalhado em sala de aula utilizando os recursos do software do GeoGebra. Nesse sentido o estudante foi direcionado à ação, ao "fazer" para "construir conhecimento". Foram disponibilizadas as sequências didáticas e, a partir delas o estudante deveria executar as construções. Na medida em que surgia alguma dificuldade para realizar a atividade, o estudante poderia fazer questionamentos, tanto em relação às ferramentas do software quanto aos conceitos trigonométricos; e também, ir além da atividade proposta, desde que, manipulasse as construções relacionadas aos conceitos basilares tratados na sequência didática - disponibilizada numa página de internet [projetopesquisagde.pbworks.com].

Para a coleta de dados foram utilizados questionários on-line via Google docs (Figura 5), os quais foram aplicados após a realização de cada oficina e, a observação direta dos estudantes durante a realização das atividades propostas. 


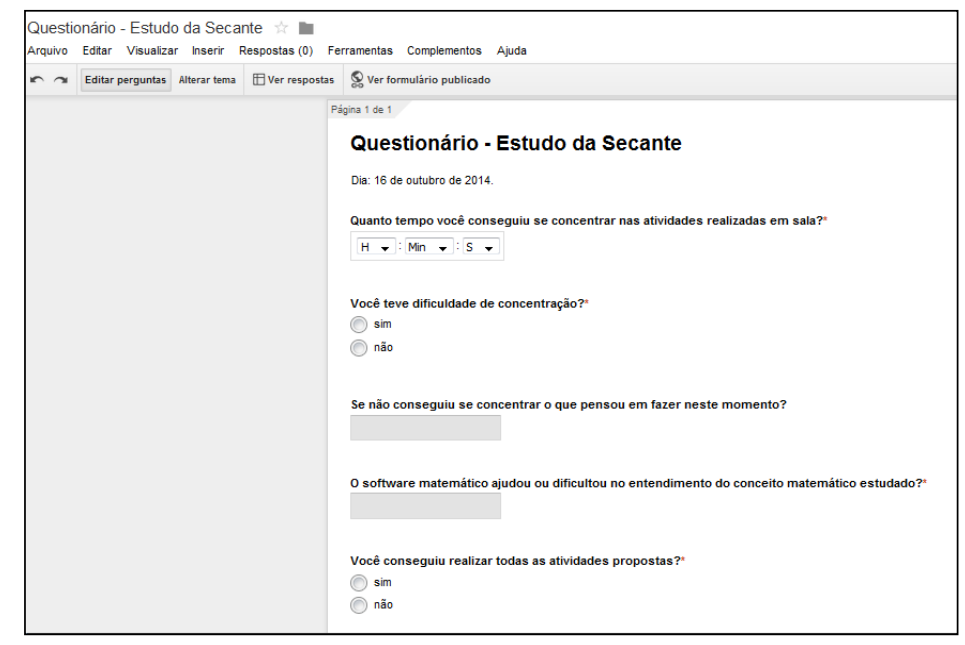

Figura 5: Recorte de questionário on-line

Os dados coletados foram registrados em uma página virtual e no drive do e-mail ambos criados especificamente para armazenar os arquivos produzidos no projeto desenvolvido. As construções produzidas no software foram enviadas por e-mail e analisadas por meio da ferramenta 'Protocolo de Construção'. O Protocolo de Construção fornece todos os passos executados pelo estudante. Logo, esta ferramenta permite ao pesquisador analisar como o estudante construiu os desenhos - se ele seguiu as etapas direcionadas na sequência didática ou encontrou outras possibilidades para resolver a atividade proposta. A partir de exercícios práticos como este, inferimos que, há outras possibilidades de verificar se o estudante foi além do sugerido na sequência de atividades.

Em todas as oficinas os mediadores explicitaram que os estudantes eram livres para realizar as atividades do modo que mais lhes despertassem a atenção, ou seja, não era obrigatório seguir a linha de raciocínio determinada pelas sequências didáticas (não foi determinado nota). A sequência didática direcionava para a construção, mas se o estudante quisesse seguir por outro caminho, ele estava livre para fazê-lo. Durante as atividades desenvolvidas nas oficinas, os conceitos trigonométricos foram trabalhados de forma dinâmica com o objetivo de despertar o interesse nos estudantes. Para tal, optamos em elaborar sequências didáticas curtas, com uma duração média de quarenta minutos.

Para dar ênfase aos conceitos trigonométricos mais importantes foram utilizadas as ferramentas com funções do software GeoGebra que tornam possíveis a movimentação. São elas: Animar, Habilitar Rastro e Controle Deslizante. Essas ferramentas proporcionam a movimentação da construção executada permitindo aprender os conceitos explorados, relacionando-se simultaneamente ao comportamento da função estudada (neste caso o rastro do ponto selecionado em função do ângulo descrito no ciclo trigonométrico) e sua representação no ciclo trigonométrico. Isso fez com que os estudantes compreendessem a relação entre os registros de representação algébrico, geométrico e discursivo (Duval, 2011). Neste sentido criamos applets as quais são construções geométricas que mantêm as propriedades iniciais da construção, sob a ação de movimentos (Figura 6). 


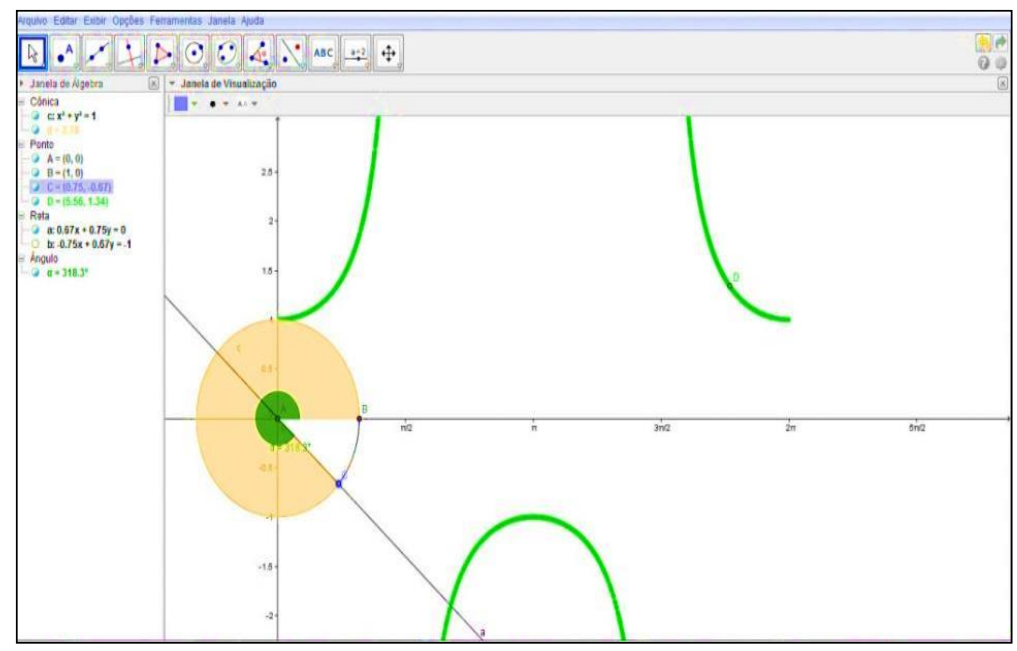

Figura 6: Construção da função secante no software GeoGebra

Estas construções foram criadas para enfatizar os conceitos trigonométricos, conforme ilustrado (Figura 6), onde o ângulo se altera constantemente em sua representação no ciclo, ao mesmo tempo em que a função é descrita pelo rastro de um ponto em movimento na janela de visualização.

As figuras estáticas da interface do GeoGebra destacadas neste artigo não são fiéis a dinamicidade que o software proporciona. Logo, dispomos na Figura 6 a imagem de um objeto matemático, a qual ilustra o movimento proporcionado pelo software, apresentando o deslocamento de um ponto sobre o ciclo trigonométrico determinando um ângulo $\alpha$, ao mesmo tempo em que outro ponto descreve uma trajetória por meio de seu rastro em função do ângulo.

Este dinamismo do software permite ao estudante fazer conjecturas e estabelecer relações entre o registro algébrico na Janela da Álgebra e o gráfico na Janela de Visualização do software. De acordo com Duval (2011) quando o estudante fizer a conversão do registro algébrico para o gráfico, e do registro gráfico para o algébrico, ele estará efetivamente aprendendo em Matemática. Neste sentido o estudante percebe que um objeto matemático pode ter diversas representações, não confundindo o objeto com sua representação.

Diversos estudos têm sido realizados com a utilização do GeoGebra, dentre os quais citamos Medeiros (2012), Abar (2013) e Gravina (2015), destacando o seu potencial semiótico na construção de conceitos matemáticos. Além disso, recentes estudos tais como: Silva (2015) enfatiza que a utilização de construções de objetos virtuais no GeoGebra oportunizaram aos sujeitos envolvidos que construíssem gradual e significativamente os conceitos matemáticos; e Medeiros (2016) afirma que o GeoGebra permite ao professor verificar todos os passos realizados pelos estudantes para desenvolver a construção e que também este ambiente de geometria dinâmica propicia a construção de conhecimento, pois o sujeito participa ativamente.

$\mathrm{Na}$ seção seguinte, apresentamos a análise dos resultados das informações que foram observadas e coletadas. Logo, discutimos sob as potencialidades do software na construção dos conceitos estudados. 


\section{Resultados e Discussões}

As aplicações das sequências didáticas foram organizadas no formato de oficinas, com duração de uma hora e trinta minutos. Sendo que, os últimos dez minutos de cada oficina foram destinados ao preenchimento do questionário on-line. A observação direta com o apoio dos questionários permitiu analisarmos alguns aspectos. Os mais relevantes foram: o entendimento das ferramentas do software GeoGebra; tempo de concentração dispensado por eles durante as atividades; aprendizagem dos conceitos explorados; realizar o levantamento das observações dos estudantes quanto às opiniões sobre a interface do software utilizado.

Constatamos que a construção dos applets destacou-se na obtenção da atenção dos estudantes participantes em relação às demais formas de representação dos conceitos trigonométricos. Isso se deve ao fato das considerações apoiadas nas fundamentações elencadas anteriormente (Gravina, 1996; Gravina, 2011; Medeiros, 2012). Os applets oportunizam as movimentações e preservam as propriedades iniciais de construção. Essa observação foi evidenciada por meio dos questionários aplicados ao final de cada oficina, no qual os estudantes relataram que as ferramentas: Animar e Habilitar Rastro foram as que despertaram uma 'especial atenção'. Confirmamos tal percepção por meio da observação direta durante o desenvolvimento das atividades, percebemos que os estudantes estavam atentos às movimentações realizadas nos objetos construídos no GeoGebra.

Ao analisarmos os Protocolos de Construção de cada estudante foi possível concluir que, a maioria deles seguiu a sequência didática, com pequenos desvios em relação às atividades. Por outro lado, constatamos que os estudantes utilizaram outras ferramentas para executar a construção e, com isso, evidenciamos a real possibilidade que software propicia a aprendizagem do estudante. O estudante pode explorar as ferramentas e descobrir outros caminhos - além do que é sugerido pelo professor.

A partir da observação direta e dos questionários aplicados foi possível concluir que a utilização do software GeoGebra contribuiu para a aprendizagem dos conceitos matemáticos. Segundo os estudantes sua utilização proporcionou um modo diferente de aprendizado; não houve a utilização da lousa e todas as atividades foram realizadas a partir do software; com o software tornamos mais fácil verificar os conceitos matemáticos e realizar relações entre eles.

Na Figura 7 apresentamos uma dentre as produções de um determinado estudante, na qual ele fez a construção do ciclo trigonométrico destacando os arcos simétricos do segundo, terceiro e quarto quadrantes, em relação ao primeiro. Na sua construção observamos a localização do ponto $\mathrm{B}$ e os seus simétricos em relação aos eixos $x$ e $y$, localizados em outros quadrantes. Registramos que sua produção é dinâmica, um applet, ou seja, no software sua movimentação é permitida. Ao movimentar o ponto $\mathrm{B}$, os demais pontos fazem seus movimentos em função de $\mathrm{B}$, mantendo a simetria dos arcos. 


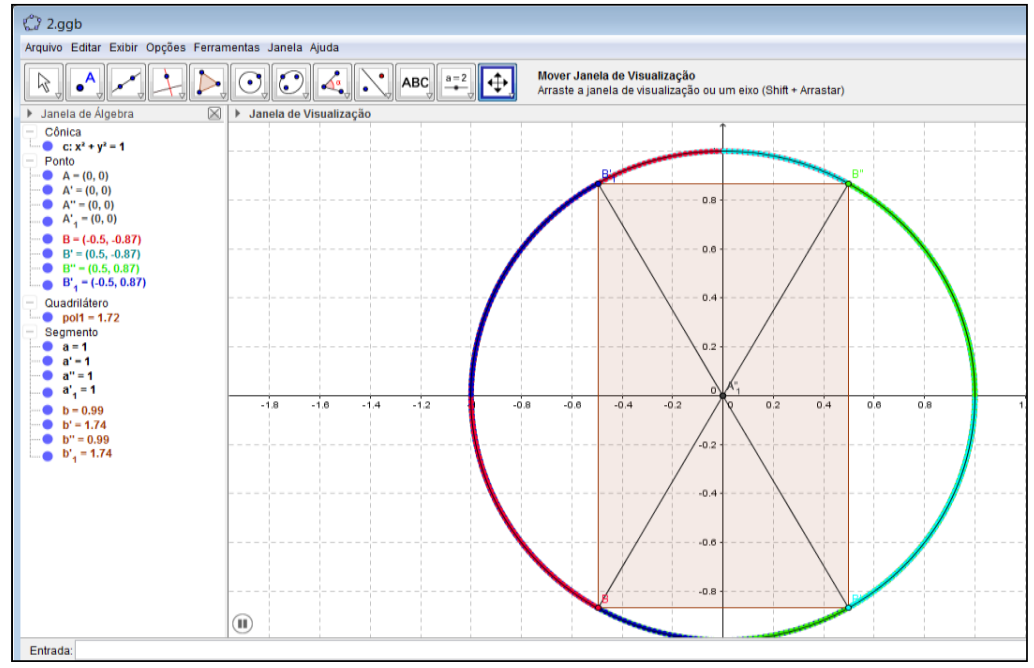

Figura 7: Representação de Arcos Simétricos utilizando as ferramentas Animar e Habilitar Rastro

Em alguns momentos de aplicação das sequências didáticas observamos que parte dos participantes desviou a atenção da atividade sugerida para explorar outras ferramentas do software GeoGebra as quais ainda não haviam sido utilizadas durante os exercícios. Estes momentos foram considerados importantes, pois estes estudantes ultrapassaram o que havia sido sugerido, ou seja, entendemos que ao se utilizar de softwares para o ensino e aprendizagem de Matemática, o estudante tem a possibilidade de buscar mais conhecimento por si próprio, não ficando limitado ao que o professor está sugerindo - ser criativo. O recurso tecnológico, o software GeoGebra, além de despertar a atenção para a construção dos conceitos geométricos oportunizou o senso de criatividade e investigação por parte do estudante, diferente de uma aula do tipo "lousa e giz".

Durante o desenvolvimento das sequências didáticas disponibilizamos um tempo para que os estudantes realizassem construções livres no software, com o objetivo de promover a familiarização com suas ferramentas. Atividades como estas e as que utilizaram a construção de applets permitiram observar que não ocorreram dispersões da atenção por parte dos estudantes participantes.

A interface do software permitiu compreender que cada objeto criado na Janela de Visualização possui sua representação algébrica. Por exemplo, no estudo do sinal da função, por meio da interface gráfica temos a representação da função e, pela Janela de Álgebra temos sua representação algébrica conforme a Figura 5. Aqui confirmamos a passagem do registro algébrico para o gráfico, ou seja, a conversão - mudança de um registro para outro. Segundo a teoria de Duval (2011), enfatizamos que houve aprendizagem.

A característica deste software apresenta-se como um diferencial em relação aos demais tipos de recursos [softwares destinados ao ensino e aprendizagem de Matemática], pois além do registro algébrico e geométrico, disponibiliza o discursivo, direcionando o estudante nas construções. Existem outros softwares os quais possibilitam a construção de gráficos, tais como o Winplot e o Graph, porém nenhum deles disponibiliza simultaneamente os registros: algébrico, geométrico e discursivo como o GeoGebra apresenta. 


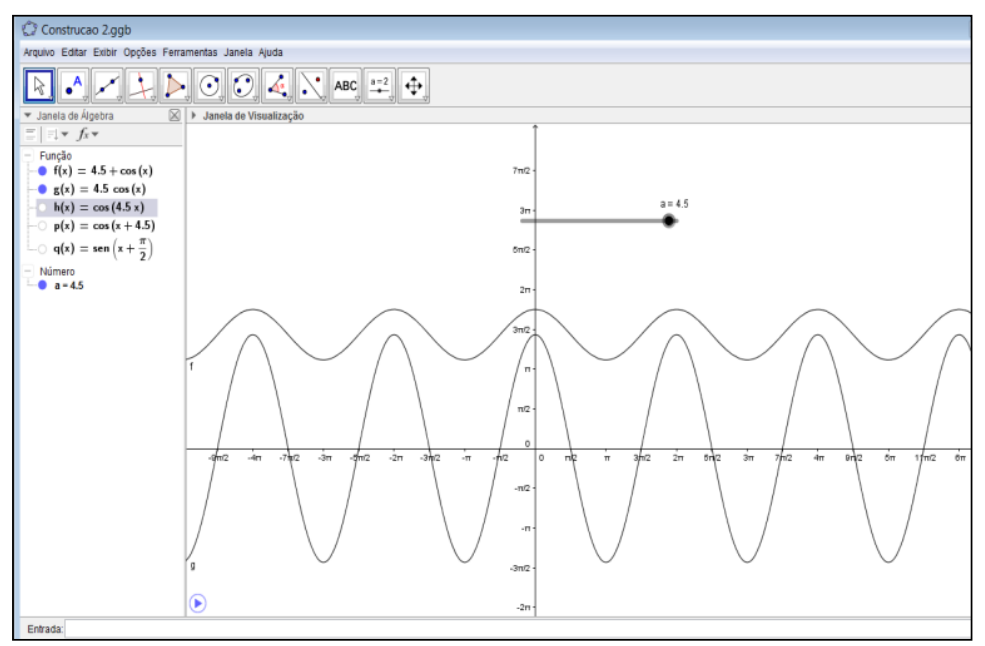

Figura 8: Representação de funções trigonométricas utilizando a ferramenta Controle Deslizante

Na Figura 8 e 9 também observamos a criação do Controle Deslizante que permite a modificação de ângulos e parâmetros da função, e neste caso, por consequência, a modificação do gráfico.

Os estudantes participantes do projeto de pesquisa conseguiram se concentrar nas atividades realizadas em média, uma hora e treze minutos. Portanto, eles estiveram em torno de $91 \%$ do tempo com a atenção voltada para a realização das sequências didáticas, visto que os dez minutos restantes eram direcionados ao preenchimento do questionário.

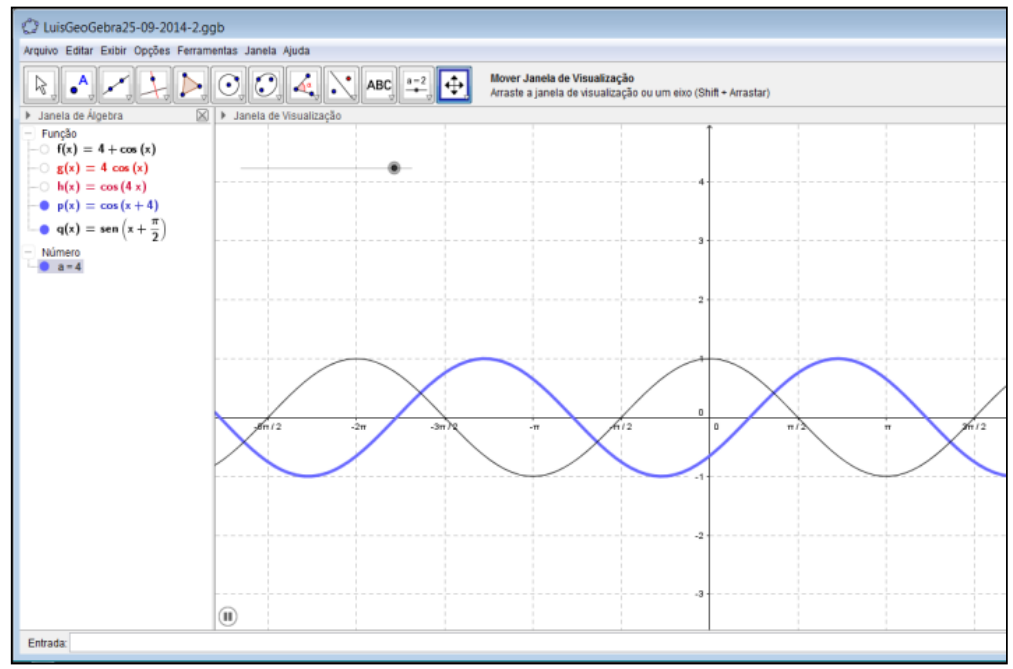

Figura 9: Representação de funções trigonométrica utilizando a ferramenta Controle Deslizante

Indagamos ainda, com relação ao uso do software GeoGebra procurando saber se utilizálo ajudou ou dificultou no entendimento do conceito matemático estudado. Neste estudo de caso, todos dos estudantes afirmaram que o GeoGebra: ajuda na construção do conceito; que a interface do software GeoGebra permite visualizar os objetos matemáticos e facilita $\mathrm{o}$ entendimento das propriedades dos objetos matemáticos estudados; possui uma interface simples com comandos fáceis de utilizar e consideraram interessante poder animar as construções criadas. Além de sugerir a utilização deste software nos demais estudos da disciplina de Matemática. 
Por outro lado, cinco estudantes disseram que não conseguiram se concentrar em todo o momento de aplicação da oficina, justificando-se por: estar pensando em trabalhos e provas e outros, por estar baixando o software no seu laptop. Ressaltamos que o projeto foi realizado em uma sala de informática em que o software já estava instalado nos computadores, contudo, alguns estudantes queriam instalá-lo [o software] em seu próprio laptop. Não foi realizada intervenção neste caso, visto que, parte da atividade foi deixá-los livres para explorar o GeoGebra. Percebemos na observação direta que este momento de dispersão não interferiu em suas aprendizagens sobre os conceitos matemáticos.

A utilização do software contribuiu ainda para aumentar o interesse pelo estudo da Matemática, pois, este proporciona uma matemática dinâmica, conforme destaca um dos estudantes: "Matemática é uma matéria que muitas vezes divide opiniões, mas acho-a uma matéria que pode ser bem dinâmica, e por esse dinamismo que eu gosto de estudar". Apesar do dinamismo do software declarado pelo estudante, a maioria deles apontou que tem dificuldade na disciplina.

Quanto às contribuições do software no estudo do conceito abordado, os estudantes afirmaram que o software contribuiu de forma significativa na visualização dos pontos e retas, como bem coloca o outro estudante: "Auxiliou por parte, durante a montagem pude notar os pontos, retas e ângulos, muito deles estudados em Matemática, mas no quadro onde visualizamos os pontos criados: tanto retas quanto ângulos e suas medidas, não têm separação de o que é cada um, dificultando de achar um ponto em vários [...]". sugerindo assim que cada ponto criado surgisse em cor diferente dos demais.

O relato dos estudantes sobre as ferramentas do software GeoGebra foram unânimes. Logo, o GeoGebra proporcionou o entendimento dos conceitos matemáticos e prendeu a atenção dos estudantes para desenvolverem as atividades propostas.

Nesta pesquisa, ressaltamos que o professor regente da turma do segundo ano não utilizava o software em suas aulas. Logo, os estudantes participantes do projeto não tiveram o acesso a este recurso tecnológico - o GeoGebra - durante suas aulas. As aulas do professor em questão permeavam entre as do tipo expositivas e dialogadas sem a utilização de tecnologia digital.

Houve vários relatos de que as ferramentas auxiliares ajudaram na visualização de gráficos e facilitaram o estudante durante o percurso da aprendizagem sobre os conceitos matemáticos funções e ângulos. Consideraram ainda que, as ferramentas do software são fáceis de utilizar e tornam as atividades mais interessantes.

Os participantes conseguiram realizar todas as atividades propostas. Parte dos estudantes necessitou de ajuda na utilização de algumas ferramentas.

Observamos que a presença do computador para trabalhar com conceitos matemáticos chamou a atenção. Papert (1994, p.73) afirma que o computador é um artefato importante "porque ele é em si um objeto interessante para explorar-se", bem como o software utilizado oportuniza ao estudante a intervenção nas construções, modificando-as, tornando-o sujeito, ele "faz". Como bem ressalta Gravina (1996, p.12): "Quanto às atitudes dos alunos frente ao processo de aprender: experimentam; criam estratégias; fazem conjecturas; argumentam e deduzem propriedades matemáticas".

Na seção que segue apresentamos as considerações sobre a efetuação da prática realizada com o software GeoGebra e a análise dos dados sob à luz das fundamentações teóricas. 


\section{Considerações Finais}

A utilização de softwares educacionais permite ao docente abordar os conceitos matemáticos de forma diferente. Os softwares de Ambientes de Geometria Dinâmica possibilitam a visualização do conceito matemático, favorecendo a construção do conhecimento. Por outro lado, o desenvolvimento prévio das atividades por parte do professor se faz necessário para que se compreenda a intencionalidade, a objetividade e desperte a curiosidade ao estudante, para impulsioná-lo e motivá-lo a aprender mais sobre os conceitos basilares da trigonometria.

Considerando o uso dos ambientes de GDE, observamos que no ensino da trigonometria a utilização do GeoGebra contribuiu para captar a atenção do estudante ao desenvolver o conceito a ser estudado por meio da sequência de atividades e reflexões sobre os detalhes desse mesmo conceito.

O software permitiu criar applets para que os estudantes prestassem atenção nas atividades propostas nas etapas consideradas primordiais para a formação dos conceitos trigonométricos. Utilizar-se das animações para explorar os conceitos trabalhados, etapas do processo de aprendizagem que exigem maior atenção dos estudantes.

Concluímos com esta pesquisa que, além da utilização do software GeoGebra contribuir para que fosse despertada a atenção nas atividades propostas, fez com que os conceitos que os estudantes participantes do projeto já haviam estudado em sala de aula ampliassem novos significados quando explorados no ambiente virtual de geometria dinâmica.

O software GeoGebra possui uma interface simples, com ferramentas fáceis de utilizar e que por meio da atividade dinâmica capta a atenção do estudante, conforme percebemos com a utilização das ferramentas Animar e Habilitar Rastro, que lhes causaram admiração. Além de não ocorrer a dispersão da atenção.

Diante dos pressupostos teóricos abordados consideramos que a atenção voluntária é essencial para a construção dos conceitos matemáticos. É por meio dela que o estudante consegue abstrair sobre as ações realizadas no software. Logo, os estudantes puderam construir os conceitos estudados.

Para os estudos futuros buscaremos realizar novas sequências didáticas com representações de objetos matemáticos de forma dinâmica, e a partir delas, sugeriremos aos estudantes que descrevam o percurso das ações de seus pensamentos enquanto estão manipulando os objetos na tela do computador. Deste modo pretendemos, além da análise nos Protocolos de Construção do software, ter detalhamento verbal sobre as ações ao longo das construções.

Também destacamos a experiência dos bolsistas envolvidos, oportunizando o aprendizado em relação ao potencial do software e aos conceitos trigonométricos. Além da participação em um projeto de pesquisa, em todas as fases de sua implementação.

Por fim, entendemos que, partir de um projeto que utilize os recursos tecnológicos como o GeoGebra, a escola tem por obrigação (ao menos possibilitar) de considerar como imprescindível disponibilizar aos estudantes recursos educacionais abertos (REA) para trabalhar nos ambientes de geometria dinâmica, visto que muitos pesquisadores, tratados neste artigo, destacaram a importância de sua utilização para que o estudante construa o conhecimento matemático. 


\section{Referências}

Abar, C. A., \& Alencar, S. V. (2013). A Gênese Instrumental na Interação com o GeoGebra: uma proposta para a formação continuada de professores de Matemática. Bolema, 349-365. [GS Search]

Bogdan, R., \& Biklen, S. (2013). Investigação Qualitativa em Educação: Uma introdução à teoria e aos métodos. Porto Alegre: Porto. [GS Search]

Borba, M. C., \& Penteado, M. (2007). Informática e Educação Matemática. São Paulo: Autêntica. [GS Search]

Duval, R. (2009). Semiósis e Pensamento Humano: Registros Semióticos e Aprendizagens intelectuais. São Paulo: Livraria da Física. [GS Search]

Duval, R. (2011). Ver e Ensinar Matemática de outra forma. São Paulo: Proem. [GS Search]

Gravina, M. A. (1996). Geometria Dinâmica: uma nova abordagem para o ensino de geometria. Anais do VII Simpósio Brasileiro de Informática na Educação, (pp. p.1-13). Belo Horizonte. [GS Search]

Gravina, M. A. (2001). Os ambientes de geometria dinâmica e o pensamento hipotéticodedutivo. Tese de Doutorado, UFRGS, Porto Alegre. [Handle] [GS Search]

Gravina, M. A. (jul/dez de 2015). O Potencial Semiótico do GeoGebra na Aprendizagem em Geometria: Uma experiência ilustrativa. VIDYA, 35(2), 237-253. [GS Search]

Machado, S. D. (2007). Aprendizagem em Matemática: Registros de representação Semiótica. Campinas: Papirus Editora. [GS Search]

Medeiros, M. F. (2012). Geometria Dinâmica no Ensino de Transformações no Plano: uma experiência com professores da Educação Básica. Dissertação de Mestrado, UFRGS, Porto Alegre. [Handle] [GS Search]

Medeiros, M. F. (2016). O Processo de Abstração Reflexionante na Construção de Conceitos Geométricos em Ambientes de Geometria Dinâmica. RENOTE, 14(2), 1-10. http://www.seer.ufrgs.br/renote/article/view/70680 [GS Search]

Miskulin, S. (2008). As possibilidades didático-pedagógicas de ambientes computacionais na formação colaborativa de professores de matemática. In: D. F. (Org), Formação de Professores de Matemática: explorando novos caminhos com outros olhares (pp. 217-248). Campinas: Mercado das Letras. [GS Search]

Moran, J. (2004). Os novos espaços de atuação do educador com as tecnologias. In: J. P. Romanowski (Ed.), Endipe, Champagnat, pp. 245-253. Curitiba. [GS Search]

Penteado, M. (1997). O computador na perspectiva do desenvolvimento profissional do professor. Tese de Doutorado, Universidade Estadual de Campinas, Campinas. [Handle] [GS Search]

Pimentel, S. (2012). Conviver com a Síndrome de Down em Escola Inclusiva: Mediação Pedagógica e Formação de Conceitos. Petrópolis: Vozes. [GS Search]

Silva, R. S. (2015). Cadeias de Markov e Modelagem Matemática: da Abstração Pseudoempírica à abstração Refletida com uso de objetos virtuais. Tese de Doutorado, UFRGS, Porto Alegre. [Handle] [GS Search]

Trouche, L. (2000). New technological environments: new constraints, new opportunities for the teacher. International Journal of Computer Algebra in Mathematics Education, pp. 165180. [GS Search] 
Valente, J. A. (1999). Análise dos diferentes tipos de softwares. In: O computador na sociedade do conhecimento. Campinas: UNICAMP. [GS Search]

Valletta, D. (2015). Desenvolvimento Profissional Docente no Contexto da Aprendizagem Ubíqua: um modelo para o Ciclo de Formação Continuada. Dissertação de Mestrado, PUC, Porto Alegre. [GS Search]

Valletta, D. (2016). Educação Digital Brasileira: possibilidades e desafios. 11, 1-12. [Handle] [GS Search]

Vygotsky, L. S. (2011). Pensamento e Linguagem. (R. C. Mores, Ed.) eBooksBrasil. [GS Search] 